\title{
Replacement Of Conceptions Developed During Health Professions Education
}

\author{
Ambreen Usmani, Maroosha Imran
}

\section{ABSTRACT:}

Replacement of concepts is another terminology used for misconceptions which are developed at an early and theoretically the student considers it as correct and builds all other related concepts upon it. This eventually become so strong that when they reach their professional studies it becomes extremely difficult to replace the misconception and erase the previously formed schema in their minds. This problem became so prominent that research into students' misconceptions started and are still continuing so as to identify the areas where replacement of concepts is required providing elaborative evidence about the nature of students' understandings This research is concentrated on particularising the essential differences between "students' and experts' ideas" on a topic that will affect lifelong learning.

\section{INTRODUCTION:}

The term misconception was widely used during this time to encapsulate the ideas that students' incorrect conceptions were often stable, widespread, resistant to change, and could interfere with learning ${ }^{1}$. The natural con- sequence of this perspective of students' ideas is that incorrect ideas should be eradicated. "If we view students' incorrect ideas as resources for refinement, rather than obstacles requiring replacement, then this model of student thinking may lead to more effective pedagogical strategies in the classroom"'.

"Research into students' misconceptions continued through the 1980s and 1990s, providing extensive information about the nature of students' understandings. Much of this research focused on describing the fundamental differences between students' and experts' ideas" ${ }^{\prime 3,4}$.

"The general consensus among education researchers during this time was that students' misconceptions were so prevalent that instruction needed to focus on revealing, confronting, and replacing them"s. "Constructivism asserts that prior knowledge is the primary resource for acquiring new knowledge, but misconceptions research has failed to provide any account of productive prior ideas for learning expert concepts and has overemphasized the discontinuity between novice and expert"6.

Smith et al discovered that novices can show expert-like behaviour "in explaining how a complex but familiar physical system works". It is elaborated that previous knowledge plays a role in scientific expertise by stipulating "raw material for formulating scientific theory, supporting qualitative

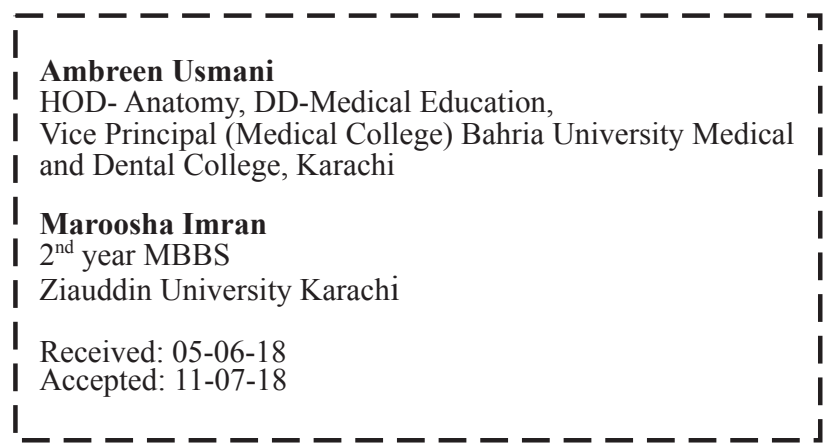

analysis", and constructing one concept over the other forming logical linkages and situations to theoretical representations $\mathrm{s}^{7,8}$. Through many examples, the researchers “demonstrated that students' conceptions are similar to complex clusters of associated ideas rather than distinguishable independent units, and replacement at that time would not be plausible or cognitively acceptable as a learning process"'. They discussed that the "mere addition of new expert knowledge and the deletion of faulty misconceptions over- simplifies the change involved in learning novel subject matter". Further backing for their claim that learning processes are much more complex than replacement suggests comes from other studies showing that "misconceptions once thought to be erased will often reappear"10.

It is incorrect to blame, that the "student's opinions about need or want are correct; rather it shows contend that the learner's initial amateur idea includes a productive component, beneficial traits that can be emphasized and built upon during instruction"11,12. The facilitator should "clarify with their students that needs or wants is overgeneralization from our own human experiences and would emphasize the role of randomness in evolutionary processes" 13 "As the concepts of need and want are relevant in our own lives", it is not possible or practical to "eradicate" the "idea from the student's mind. Instead, we need to help the learner refine or limit their application of that idea. ${ }^{14}$ Studies have shown that students may shift from one incorrect conception to another before developing scientific understanding, and such shifts can be viewed as initial steps in meaningful learning" 15 .

Andrews et al, defined misconception as "a scientifically inaccurate idea about a scientific concept" that "may occur before and after instruction".

"When biology education researchers refer to students constructing new ideas and integrating new ideas with old ones, while concurrently describing students' erroneous ideas as those to be" "challenged" and "replaced" they are demonstrating a misunderstanding although students do still have incorrect conceptions in biology, these conceptions are 
the building blocks for future knowledge and can be viewed as such standing of constructivist destruction ${ }^{16,17}$. Here the problem does not seem to be of teaching strategies or the assessment tools but it seems to be of the concepts of the students which are developed initially. These students then carry these concepts with themselves throughout their fiveyear MBBS course and also after that as working doctors. Misconceptions are a natural result of trying to make sense out of new information and ideas. ${ }^{18}$ By observation "one can make inferences about this understanding. For instance, based on observing someone take a needlessly long way to get to a location, this may infer that the person is not aware that road construction has been finished which would be a shortcut that would prove to be shorter. This inference is an example recognizing someone's misunderstanding through observation alone. The person believes that the road cannot be traversed, but in fact, the road is passable. Making inferences about the understanding and misconceptions of others can be critical in education settings as it allows one to specifically intervene and correct those misconceptions" ${ }^{\text {19,20 }}$. Observing others take actions to complete a goal and making "inferences about that person's knowledge is a relatively natural task for people. "This ability can be especially important in educational settings, where the inferences can be used for assessment, diagnosing misconceptions, providing informative feedback and applying replacement. A general framework for making such inferences based on observed actions" has been constructed by educationists; this framework is based upon "educational games and other interactive virtual environments". The basics of this model relies on action planning and performance. A scenario was formalized as a "Markov decision process in which one must choose what actions to take to complete a goal, where choices will be dependent on one's beliefs about how actions affect the environment ${ }^{21}$. A variation of inverse reinforcement learning to infer these beliefs were used". Laboratory experiments, showed that this model can recover "people's beliefs in a simple environment", with accuracy as opposed to observation ${ }^{22}$. It was later demonstrated that "the model can be used to provide real-time feedback and to gather model data from an existing educational game" can be used as a reliable tool in replacing misconceptions. ${ }^{23}$ Making conclusions and inferences about the understanding of students can be critically upsetting in education settings as it allows one to particularly interfere to correct those misconceptions ${ }^{19,20}$. An easy way of understanding this problem is: imagine students playing a scientific virtual game, and their "responses to specific situations in the game, such as what sequence of actions is taken to adapt an organism to a new environment, can indicate their knowledge about particular elements of cell biology". If any student of the entire class never makes particular "adaptations or takes actions in a suboptimal order, this can indicate gaps in their knowledge, leading to targeted remediation"; conversely, the students' actions might indicate that they might have mastered the current topic and are ready for the next activity ${ }^{24}$. Automating these "assessments is beneficial because it does not require interrupting students to explicitly query their knowledge and can provide a detailed picture of students' misconceptions". The benefits of "stealth assessments" that occur within a student's normal activities have been noted, ${ }^{25}$ and prior work has found that such embedded assessments can be useful in the classroom ${ }^{26}$.

The "ability to use complex series of actions to automatically diagnose student knowledge is becoming more relevant with the increasing use of games and the electronic environments in education. Within these environments, students often perform many individual actions to complete a task, resulting in appropriate data about the choices that students make. These data contain much more information than simply whether the student completed the task successfully or not, and we would like to use these data to make fine- grained inferences about a student's knowledge, including misconceptions, just as a teacher could infer this information by observing the student. However, existing assessment models in education are generally not suited to interpreting such sequential process data. These models typically assume the data are conditionally independent given student ability, and consider only success or failure, rather than the way that these outcomes are achieved ${ }^{27,4,8}$. Instead, we propose modelling the process by which people choose their actions based on their beliefs. This detailed model then allows us to gain insight into a student's knowledge by observing her actions". "Cognitive Load Theory (CLT) has started applications in medical education research, unfortunately, misconceptions such as lower cognitive load always is beneficial to learning and the continued use of dated concepts and methods can result in improper applications of CLT principles in medical education design and research" may be questionable ${ }^{28}$.

\section{METHODOLOGY:}

"Literature search was performed by using database of PubMed", the keyword use was misconception (56 searches) AND learning (143 searches). "PERN was used by database of Bahria University, this included literature and articles from international sources; 2 articles from Pakistan on this topic were consulted (one in international journal and 1 in a local journal)". Of these, 49 articles were shortlisted which discussed relation replacement of conception developed during health professions education. "These articles were consulted for this review".

\section{LITERATURE REVIEW:}

Q-Why do students have these misconcept-ions?

Reports by researchers in science education suggest that students' misconceptions are often stable, pervasive and resistant to change $\mathrm{e}^{29,1}$. "Teachers can be astonished to learn that despite their best efforts, students do not grasp fundamental ideas covered in class. Even some of the best 
students give the right answer but are only using correctly memorized words. When questioned more closely, these students reveal their failure to understanding fully the underlying concepts ${ }^{2,25}$. Students' "misconceptions about scientific phenomena can arise from at least two possible sources, the students personal experience with those phenomena and things learned in the classroom. Misconceptions have been studied in a variety of science disciplines, but little attention has been given to the faulty models",3, 6,28.

Q-Why Do Misconceptions Occur Anyway?

Misconceptions can be categorized as follows ${ }^{3,9,16}$;

"PRECONCEIVED NOTIONS are popular conceptions rooted in everyday experiences".

NONSCIENTIFIC BELIEFS "include views learned by students from sources other than scientific education, such as religious or mythical teaching"

CONCEPTUAL MISUNDERSTANDINGS arise when students are taught scientific information in a way that does not provoke them to confront paradoxes and conflicts resulting from their own preconceived notions and nonscientific beliefs. To deal with their confusions, students construct faulty models that usually are so weak that the students themselves are insecure about concepts.

Vernacular misconceptions arise from the use of words that mean one thing in everyday life and another in a scientific context".

Factual misconceptions are falsities often learned at an early age and retained unchallenged into adulthood.

Whenever students are unable to structure the huge amount of information that they acquire and store in their long-term memory, misconceptions about topics or subjects may occur since this structuring of knowledge is one of the most important cognitive themes for education ${ }^{30}$.

Thus, it is very difficult to attribute the reason for misconceptions to one problem, it may be a set of problems, which need to be identified, followed-up and solved. "We show how?mass spectrometry and infrared spectroscopy allow for? unravelling the chemical background of this demonstration? and discuss various ideas on how to use it in a classroom setting?to engage students' critical thinking about chemical research.?Along the way, we show that two commonly published ideas?about the chemical background of this demonstration are incorrect, and we suggest simple tests that may be performed in a high school setting either as an addition to the demonstration or as a student research project. There is, however, another major benefit to implementing this demonstration in a high school curriculum. When continuing the classroom discussion following the demonstration, questions that relate to and connect many aspects of the curriculum will arise. While a survey of the literature suggests that experimental variables have been explored rather well for this demonstration, the provided explanations, among others in this Journal, are highly doubtful. A guided classroom discussion will bring this to light. We discuss two obvious questions within the framework of such a classroom discussion, assuming a knowledge level characteristic for students nearing graduation. We conclude with the notion that this demonstration has beautiful complexity and wide applicability veiled by an apparent simplicity".

This study investigated undergraduate biology students' conceptions of Genetically Modified Organism (GMOs), and how those conceptions can be compared to the spectrum of biology expertise. However, this study represents only the conceptions of undergraduate nonmajors, biology majors, and faculty from one institution and should be explored across a broader range of disciplines and contexts. The authors omitted participant attitudes toward GMOs from the analysis to focus on conceptual understanding ${ }^{31}$.

Every day biology undergraduates learn from lectures halls, libraries, and laboratories with their minds abuzz with biological concepts. Yet the degree to which students apply those concepts to everyday life is an open question. Indeed, from healthcare to climate change to biotechnology, the challenges facing modern society demand an expertise in underlying biological principles in order to be able to perform solutions. Partly for this reason, the collaboratively published document Vision and Change in Undergraduate Biology Education has urged biology educators to encourage expert thinking in their students ${ }^{32}$.

"Experts connect ideas from diverse subjects to build their worldviews ${ }^{33}$. Previous studies have shown that using relevant biological problems as learning tools can help bridge the gap between science learned in the classroom and the real world"34. "While many examples of such biological problems exist, genetic modification in particular is a complex concept that relies on in-depth understanding of the molecular behavior of DNA and proteins ${ }^{35}$. At the core of this understanding is what is often termed "the central dogma," which describes how information is stored in DNA, copied into a newly built RNA molecule, and used to make proteins that carry out cellular functions. Many educators may assume that students with a biology degree are more equipped to understand the complex science behind genetically modified organisms (GMOs) than the general public; however, the central dogma has been a well-documented challenge for undergraduates ${ }^{36}$.

"In India, traditional contraceptive methods are employed by a large population, and most of the time decisions related to family planning are taken by the men of the household. Therefore, it is really necessary for men to have the correct idea of when a woman is most susceptible to pregnancy during the menstrual cycle. The study tries to assess the prevalence of such knowledge among urban men in Uttar 
Pradesh, India. Also, it attempts to investigate the rationale behind the misconceptions among men of the region under study. It was found that only one-fifth of the men have the correct knowledge about the concept. Further, education, societal perception, caste, and spousal discussion about the reproductive issues are found to be the most important components that affect the knowledge among men about the conception risk during the menstrual cycle ${ }^{37}$. The study suggests promoting the sex education in urban Uttar Pradesh, especially in slum areas to educate the men regarding the reproductive functions of women. Also, the article promotes higher education and motivates couples to discuss the reproductive hurdles among them. These interventions can provide a better reproductive health to the women of urban Uttar Pradesh, India".

"Educational studies about virus-related issues have hitherto also mostly been interested in knowledge about ways of transmission and prevention of infection. Only a very limited number of studies analyzed students' biological knowledge about viruses (e.g. virus structure as distinct from pro/eukaryotes, the cellular infection process, details about the immune system response), and, if so, usually focused on single or few aspects only" ${ }^{38}$. As far as we know, very few studies have analyzed the relevant knowledge in depth and tried to improve understanding concerning virus biology, with, however, a very limited number of participants? $\mathrm{N}=$ 10-54 in various studies). Here, we attempted to make visible such knowledge in a much broader way, both within and between three age groups of students (high school grade 7, high school grade 10, biology and non-biology first-year university students). "Due to the large number of participants we were able to both derive quantitative measures and qualitative data from distributed questionnaires, which comprised mostly open-response items.

A second reason for this study was cumulative evidence that many clinicians and general practitioners sometimes unnecessarily prescribe antibiotics, e.g. for patients with acute respiratory infections ${ }^{39,40,41}$.

"Misconceptions can impede student learning and?are refractory to change, they are seldom measured in biomedical courses". Scientific literacy is the ability to navigate, interpret, and critique scientific information-skills critical for all citizens as they support scientifically informed decisionmaking. One emerging genre of citizen science (i.e., the inclusion of non-scientists in research to meet shared goals $)^{4,13}$ is inquiry-based research in undergraduate laboratory courses $^{14,19}$. Through this work, students experience the true nature of science through the failures and successes of authentic research. Although such experiences are powerful students may not appreciate their greater impact-i.e., the breakdown of barriers between science and society to create engaged citizens and a more balanced scientific process.

ANYONE WHO HAS TAUGHT NEUROPHYSIOLOGY would be aware of recurring concepts that students find difficult to understand. However, a greater problem is the development of misconceptions that may be difficult to change. ${ }^{7}$ For example, one common misconception is that action potentials pass directly across chemical synapses. ${ }^{8}$ Difficulties may be compounded by explanations using voltage-time graphs, since students are not necessarily familiar with oscilloscope or computer-based representations of neural signals. Several different approaches have been used to overcome such misconceptions and provide simple explanations of complex physiological processes. These range from using groups of students acting out concepts ${ }^{14}$ to the use of a "travelling flame" analogy for nerve conduction $^{11}$. E-learning using animations provides an additional method for overcoming physiology misconceptions. Internet-based instruction in the health professions may be similar to traditional instruction in effectiveness, ${ }^{3}$ but it is important to clarify when to use elearning and how to use it effectively ${ }^{2}$. Thus, an "online self-directed e-learning module was developed, using bestpractice approaches $\mathbf{1}$, to engage students and help them overcome some common neurophysiology misconceptions. The essential features of the module were: the use of welldesigned ${ }^{9}$ and simple (low cognitive load) ${ }^{\mathbf{1 2}, 13}$ animations intended to promote good learning outcomes ${ }^{5}$ and the use of multiple-choice questions linked with the animations to provide immediate feedback"

Inter professional "SRC participation promotes learning 'with, from, and about' each other. Participation challenges misconceptions and sensitizes students to patient experiences, health systems, advocacy, and social responsibility. Learning involves inter professional interactions "in the patient encounter, reinforced by formal and informal communications. Participation is associated with interest in serving the underserved and in primary care careers. The authors proposed a framework for inter-professional learning with implications for optimal learning environments to promote team-based care. Future research is suggested to identify core faculty functions and best settings to advance and enhance student preparation for future collaborative team practice".

\section{CONCLUSION:}

Replacement of misconception is a challenging task especially at the level of University students, however it is important to identify those students who have built their misconception but in their minds the schema is correct and they continue to build upon these tasks which is difficult to erase in their minds and ensure that they have accepted the new correct concept and understanding of a topic they have been learning for many years.

\section{REFERENCES:}

1. Tekkaya. Changing students' scientific misconceptions. Sc and Tech Educ. 2003; 21:5-16. 
2. Michael JA. Students' misconceptions about perceived physiological responses. Advan Physiol Edu. 1998; 274:90S98S.

3. April Cordero Maskiewicz and Jennifer Evarts Lineback Misconceptions Are "So Yesterday!" CBE-Life Sc Educ. 2013;12: 352-356

4. Misconceptions as barriers to understanding science. Science. Teaching reconsidered: A handbook-4.

5. Spierenburg R, Jacobse L, Iris de Bruin, Daan J. van den Bos, Dominique M. Vis, Ludo BFJ. Misconceptions in the Exploding Flask Demonstration Resolved through Students' Critical Thinking. J Chem Educ. 2017; 94:1209-1216. Doi: 10.1021/acs.jchemed.7b00281

6. Baker CL, Saxe RR, Tenenbaum JB. Action understanding as inverse planning. Cognition. 2009;113(3):329-349.

7. Lan AS, Waters AE, Studer C, Baraniuk RG. Sparse factor analysis for learning and content analytics. J of Mac Learning Res, 2014;15:1959-2008.

8. Rafferty AN, Michelle ML, Thomas LG. Cog Sc.Cognitive Science Society, Inc. All rights reserved. Inferring Learners' Knowledge from Their Actions. 2015;39:584-618. DOI: $10.1111 / \operatorname{cogs} .12157$

9. Agorram B, Clement P, Selmaoui S, Khzami SE, Cha KJ, Chiandli A. University students' conceptions about the concept of gene: Interest of historical approach. US-China Educ Rev, 2010;7(2): 9-15.

10. Danielson KI, Tanner KD. Investigating undergraduate science students' conceptions and misconceptions of ocean acidification. CBE — Life Sc Edu, 2015;14(3): ar29.

11. Sinatra GM, Kienhues D, Hoferm BK. Addressing challenges to public understanding of science: Epistemic cognition, motivated reasoning, and conceptual change. Educ Psychol, 2014; 49:123-138.

12. Southard K, Wince T, Meddleton S, Bolger MS.. Features of knowledge building in biology: Understanding undergraduate students' ideas about molecular mechanisms. CBE-Life Sc Educ, 2016;15(1):ar7.

13. Coley JD, Tanner KD. Relations between intuitive biological thinking and biological misconceptions in biology non-majors. CBE-Life Sc Educ. 2015;14(1): ar8.

14. Danielson KI, Tanner KD. Investigating undergraduate science students' conceptions and misconceptions of ocean acidification. CBE_- Life Sc Educ, 2015;14(3): ar29.

15. Little P, Stuart B, Francis N, Douglas E, Tonkin-Crine S, Anthierens S, et al. Effects of internet-based training on antibiotic prescribing rates for acute respiratory-tract infections: a multinational, cluster, randomised, factorial, controlled trial. Lancet. 2013; 382: 1175-82. doi.org/10.1016/S0140-6736 (13)60994-0?

16. Andrews TM, Price RM, Mead LS, McElhinny TL, Thanukos A, Perez KE, Herreid CF, Terry DR, Lemons PP. Biology Undergraduates' Misconceptions about Genetic Drift CB. Life Sc Educ. 2012;11:248-259

17. Bedard J, Chi MTH. Current Directions in Psychological Science, Expertise. 1992;1:135-139.

18. Zeidler DL, Sadler TD, Simmons ML, Howes EV. Beyond STS: A research-based framework for socioscienti c issues education. Science Education, 2005;89:357-377.

19. Newman DL, Catavero CM, Wright LK. Students fail to transfer knowledge of chromosome structure to topics pertaining to cell division. CBE-Life Sc Educ. 2012;11: 425-426.

20. Newman DL, Snyder CW, Fisk JN, Wright LK. Development of the Central Dogma Concept Inventory (CDCI) assessment tool. CBE— Life Sc Educ. 2016;15(2): ar9.

21. De ì sire ì e AL, Christopher PF, Walsh A, Banzali Y, Lohenry $\mathrm{K}$. What and how do students learn in an inter professional student-run clinic? An educational framework for team- based care. Med Educ Online 2016;21:3190 doi.org/10.3402/meo. v21.31900?

22. Verma P, Kumar Singh K, Singh A. Pregnancy risk during menstrual cycle: misconceptions among urban men in India. Reprod Health. 2017;14:71. doi 10.1186/s12978-017-03323

23. Uwe KS, Sonja ME, Fink A. "The evil virus cell": Students knowledge and beliefs about viruses. PLOS ONE. 2017 doi.org/10.1371/journal.pone.0174402

24. Tobin EA, Okojie HO. Knowledge, attitude and practices of adolescent secondary school students in Uvwie local government area of delta state to HIV/AIDS. Ben J Postgrad Med. 2010; 12: 43-52. ?

25. Linder JA, Doctor JN, Friedberg MW, Nieva HR, Birks C, Meeker D et al. Time of day and the decision to prescribe antibiotics. JAMA Intern Med. 2014; 174: 2029-2031. doi.org/10.1001/ jamainternmed.2014.5225?

26. Potter LM, Bissonnette SA, Knight JD, Tanner KD. Investigating Novice and Expert Conceptions of Genetically Modified Organisms CBE-Life Sc Educ. 2017;16:ar52:1-13

27. Curtis DA, Samuel LL, Dellinges M, Schroeder K. Identifying Student Misconceptions in Biomedical Course Assessments in Dental Education Educational Methodologies. J of Dent Educ 2012; 76(9):1183-1194

28. Leppink J, Angelique van den Heuvel. The evolution of cognitive load theory and its application to medical education Perspect Med Educ. 2015;4:119-127 doi 10.1007/s40037015-0192-x.

29. Stephanie B, Stockwell J, Madison A. Progressive Reading, Writing, and Artistic Module to Support Scientific Literacy Journal of microbiology \& biology education, 2016;93-97. doi: http://dx.doi.org/10.1128/jmbe.v17i1990.,

30. Ahmed H, Fasih A, Khatri R. Misconceptions concerning maternal and child health in low socioeconomic status societies. J Coll Physicians Surg Pak. 2010;20(12):835-6. doi: 12.2010/JCPSP.835836.

31. Nadeem NJ. The Global Polio Eradication Initiative (GPEI) in Pakistan. J Pak Med Assoc. 2016;66(11):1466-1471.

32. Richard Guy. Overcoming misconceptions in neurophysiology learning: an approach using color-coded animations. Illuminations. Adv Physiol Educ. 2012;36:226-228. doi:10.1152/advan. 00047.2012

33. Leonard MJ, Kalinowski ST, Tessa C. Andrews CBE-Life Sc Educ 2014;13:179-186, Summer. Misconceptions Yesterday, Today, and Tomorrow doi: 10.1187/cbe.13-120244

34. Stuart O'Connor, Kenneth CA. Peer-led live research demonstrations: challenging medical student misconceptions about research. Perspect Med Educ. 2016;5:60-62 doi 10.1007/s40037-015-0239-Z

35. Briggs AG, Morgan SK, Sanderson SK, Schulting MC, 
Wieseman LJ. Tracking the Resolution of Student Misconceptions about the Central Dogma of Molecular Biology. Journal of microbiology \& biology education. 2016;339-350 doi: dx.doi.org/10.1128/jmbe.v17i3.1165

36. Young T, Rohwer A, Susan van Schalkwyk, Volmink J, Clarke M. Patience, Persistence and Pragmatism: Experiences and Lessons Learnt from the Implementation of Clinically Integrated Teaching and Learning of Evidence-Based Health Care - A Qualitative Study. PLOS ONE. 2015. doi:10.1371/ journal.pone.0131121

37. Medha Kumar and Varun Dutt. Hypothesis and theory published: Experience in a Climate Microworld: Influence of Surface and Structure Learning, Problem Difficulty, and Decision Aids in Reducing Stock-Flow Misconceptions. 2018. doi: 10.3389/fpsyg.2018.00299

38. Meadows D, Sweeney LB, Mehers GM. The Climate Change Playbook. White River Junction, VT: Chelsea Green Publishing. 2016.
39. Katrina Weston-Green and Margaret Wallace A method of providing engaging formative feedback to large cohort firstyear physiology and anatomy students. Adv Physiol Educ. 2016;40: 393-397, doi:10.1152/advan.00174.2015.

40. Jordan J. The Use of Orally Recorded Exam Feedback as a Supplement to Written Comments. 2016. http://www.amstat .org/publications/jse/ v12n1/jordan.html

41. American Association for the Advancement of Science. 2011. Vision and Change in Undergraduate Education: A Call to Action. Washington, DC. Cited January 18, http://visionandchange.org/ nalreport

42. Mansoor SN, Rathore FA. Myths and misconceptions regarding facial nerve palsy management: Interesting perspectives from a developing Country. J Neurosci Rural Pract. 2015;6(3):4545. doi: 10.4103/0976-3147.158756.

43. Tonkin-Crine S, Walker AS, Butler CC. Contribution of behavioural science to antibiotic stewardship - Belated recognition of its importance. BMJ. 2015; 350: h3413. doi.org/10.1136/bmj.h3413 